\title{
The $-174 \mathrm{G} / \mathrm{C}$ gene polymorphism in interleukin-6 is associated with an aggressive breast cancer phenotype
}

\author{
B lacopetta ${ }^{*, 1}$, F Grieu² and D Joseph ${ }^{2}$ \\ 'School of Surgery and Pathology, University of Western Australia, Nedlands 6009, Australia; ${ }^{2}$ Department of Radiation Oncology, Sir Charles Gairdner \\ Hospital, Nedlands 6009, Australia
}

\begin{abstract}
Serum and tissue levels of interleukin-6 (IL-6) have been implicated in the biological phenotype of breast carcinoma. A common G/C polymorphism at position - 174 of the $I L-6$ promoter can influence the expression level of this gene. We therefore investigated for associations between this polymorphism and various phenotypic features in a series of 256 breast cancers. Individuals who were homozygous for the $C$ allele $(n=55)$ were more likely to have higher-grade tumours $(P=0.039)$ with ductal histology $(P=0.030)$ compared to those harbouring at least one wild-type $G$ allele $(n=201)$. Homozygosity for the $C$ allele was also associated with significantly worse overall survival $(P=0.03 \mathrm{I})$. We conclude that the $-174 \mathrm{C}$ allele of IL-6 is associated with a more aggressive breast cancer phenotype.

British Journal of Cancer (2004) 90, 419-422. doi:I0.1038/sj.bjc.660I545 www.bjcancer.com

(C) 2004 Cancer Research UK
\end{abstract}

Keywords: interleukin-6; polymorphism; breast cancer; prognosis

Interleukin-6 (IL-6) is a pleiotropic growth factor involved in many physiological and pathological processes including carcinogenesis (Ishihara and Hirano, 2002). High serum levels of IL-6 have been associated with advanced stage disease and worse prognosis for several cancer types including ovarian, breast and colorectal (Berek et al, 1991; Zhang and Adachi, 1999; Belluco et al, 2000; Bachelot et al, 2003). In contrast, however, high levels of IL-6 protein and mRNA expression within the breast carcinoma tissue have been linked to better prognosis and to a less malignant phenotype (Basolo et al, 1996; Fontanini et al, 1999; Karczewska et al, 2000).

A common G/C polymorphism located within the $I L-6$ promoter at position -174 has been reported to influence IL- 6 expression, with the $G$ allele being associated with higher expression levels (Fishman et al, 1998; Terry et al, 2000; Vickers et al, 2002). This polymorphism has been implicated in a number of chronic disease conditions including arthritis, coronary heart disease and diabetes (Fishman et al, 1998; Fernandez-Real et al, 2000; Yudkin et al, 2000). In human cancer, the -174 G/C IL-6 polymorphism does not appear to be a risk factor for the development of multiple myeloma or melanoma (Zheng et al, 2000; Martinez-Escribano et al, 2002). Recent data, however, suggest that the $C$ allele is associated with an increased risk of colorectal cancer (Landi et al, 2003). Furthermore, in ovarian cancer, the $C$ allele is associated with an earlier stage of disease and with significantly better survival (Hefler et al, 2003). In light of the earlier studies linking serum and tissue IL-6 levels to breast cancer outcomes, the aim of the present study was to investigate for possible associations

*Correspondence: Dr B lacopetta; E-mail: bjiac@cyllene.uwa.edu.au Received 14 July 2003; revised 15 October 2003; accepted 5 November 2003 between the -174 G/C IL-6 polymorphism and phenotypic characteristics of breast cancer.

\section{MATERIALS AND METHODS}

\section{Breast cancers}

Consecutive cases of breast cancer treated surgically between 1992 and 1993 at the Sir Charles Gairdner or Royal Perth Hospitals in Perth, Australia, were selected for study. Genomic DNA was extracted from surgical specimens using standard techniques. The median age of patients at surgery was 59 years (range $18-93$ years) and the median follow-up time was 57 months (range 2-96 months). Clinical and pathological features of this tumour series have been described earlier (Soong et al, 1997). Approximately $92 \%$ of node-positive and $23 \%$ of node-negative patients received some form of systemic adjuvant therapy. The majority of patients (>95\%) were of European Caucasian descent. Successful genotyping of the -174 G/C IL-6 polymorphism was achieved for 256 cases. Of these, information on nodal status was unavailable for 61 cases, histological grade for 54 cases, histological type for 23 cases, tumour size for 27 cases, oestrogen and progesterone receptor status for five cases, ploidy for 98 cases, vascular invasion for 45 cases and erbB2 status for 25 cases. An institutional ethics committee approved the study.

\section{Genotyping for the -174 G/C IL-6 polymorphism}

Genotyping for the -174 G/C IL-6 polymorphism was carried out using a PCR-based fluorescence (F)-SSCP protocol, essentially as described earlier by our laboratory for other single-nucleotide polymorphisms (Powell et al, 2002; Grieu et al, 2004). HEXlabelled fluorescent primers (Geneworks, Australia) were designed 
to span the polymorphism and give rise to a PCR product of $165 \mathrm{bp}$ in size. The forward primer sequence was $5^{\prime}$-AGGAAGAGTGGTTCTGCTTC- $3^{\prime}$ and the reverse primer sequence $5^{\prime}$ CTTTGTTGGAGGGTGAGGGTG-3'. PCR was carried out in a volume of $15 \mu \mathrm{l}$ comprising a mix of $1 \times$ reaction buffer, $0.2 \mathrm{~mm}$ dioxynucleotide triphosphates, $2.5 \mathrm{mM} \mathrm{MgCl}_{2}, 0.4 \mu \mathrm{M}$ of each primer and $0.3 \mathrm{U}$ Taq polymerase (Qiagen, Australia). Samples were heated to $94^{\circ} \mathrm{C}$ before addition of DNA template 200 (200 ng). PCR comprised $10 \mathrm{~min}$ of denaturation at $94^{\circ} \mathrm{C}$ followed by 32 cycles of $45 \mathrm{~s}$ at $94^{\circ} \mathrm{C}, 45 \mathrm{~s}$ at the $64^{\circ} \mathrm{C}$ annealing temperature and $45 \mathrm{~s}$ at $72^{\circ} \mathrm{C}$. Final extension was at $72^{\circ} \mathrm{C}$ for $5 \mathrm{~min}$.

For F-SSCP, $2 \mu \mathrm{l}$ of PCR product was mixed with $4 \mu \mathrm{l}$ of deionised formamide-loading buffer and denatured at $94^{\circ} \mathrm{C}$ for $3 \mathrm{~min}$. A volume of $1 \mu \mathrm{l}$ of this mix was then loaded onto a nondenaturing $10 \%$ polyacrylamide gel and run on the Gel-Scan 2000 DNA fragment analyzer, according to the manufacturer's instructions (Corbett Research, Australia). The sample was pulse loaded for $20 \mathrm{~s}$ at $1200 \mathrm{~V}$, the wells rinsed and the gel run for $90 \mathrm{~min}$ at $1200 \mathrm{~V}$ in $0.8 \times$ TBE buffer at a constant temperature of $22^{\circ} \mathrm{C}$. Sequencing of four DNA samples displaying homozygous banding patterns on F-SSCP gels was carried out in order to identify the three possible $-174 \mathrm{G} / \mathrm{C} I L-6$ genotypes.

\section{Statistical analysis}

The $\chi^{2}$ test (Pearson statistic) was used to determine associations between the -174 G/C IL-6 polymorphism and various clinical and pathological features of the breast tumours. Kaplan-Meier analysis was used to assess the cumulative survival probabilities and differences were evaluated using the log-rank test. Cox regression was used in univariate survival analysis of various established prognostic factors and for the $-174 \mathrm{G} / \mathrm{C} I L-6$ genotype. All $P$-values are derived from two-tailed statistical tests. Analyses were carried out using the SPSS statistical software package (Chicago, IL, USA).

\section{RESULTS}

Three distinct banding patterns could be seen for the $-174 \mathrm{G} / \mathrm{C} I L$ 6 polymorphism using the F-SSCP genotyping method (Figure 1). DNA sequencing identified these as CC homozygotes (pattern 1), GG homozygotes (pattern 3) and the GC heterozygote (pattern 2). Frequencies for the $\mathrm{C}$ and $\mathrm{G}$ alleles were 0.43 and 0.57 , respectively, and were in Hardy-Weinberg equilibrium. The $\mathrm{C}$ allele frequency has previously been reported as 0.41 in a large $(n=1109)$ community-based Australian study (Chapman et al, 2003), 0.43 in a UK study of 588 individuals (Vickers et al, 2002), 0.40 in another UK study of 383 healthy individuals (Fishman et al, 1998) and 0.43 in a study of 121 ovarian cancer patients from Austria (Hefler et al, 2003).

Tumours showing nonductal histology or well-differentiated morphology were significantly under-represented in patients who were homozygous for the $\mathrm{C}$ allele (Table 1). Only one out of 25 (4\%) tumours with nonductal histology were found in CC homozygous patients compared to 47 out of 208 (23\%) tumours with ductal histology $(P=0.03)$. CC homozygous patients also showed trends for association with larger tumour size, low oestrogen receptor content, aneuploidy and amplified ErbB2 status, all of which are known features of poor prognosis. No associations were seen, however, with two other features of poor prognosis: positive nodal status and the presence of mutant p53.

Kaplan-Meier survival analysis revealed the $I L-6-174$ CC genotype was associated with significantly worse overall survival compared to the GG or GC genotypes $(P=0.031$, Figure 2$)$. The increased relative risk of death associated with homozygosity for the $\mathrm{C}$ allele was shown in univariate survival analysis to be 1.99 (95\% confidence interval: $1.05-3.77$; Table 2). The established

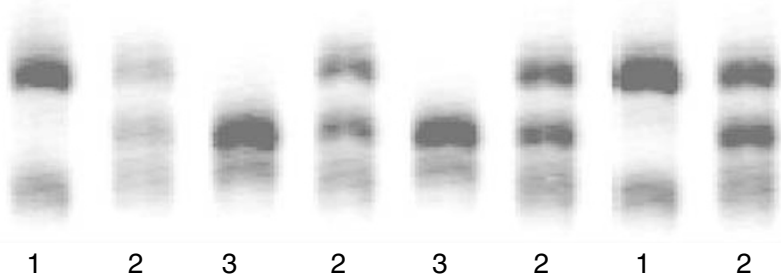

Figure I F-SSCP genotyping for the - 174 G/C IL-6 polymorphism in breast cancer patients. The three different genotypes are indicated by the banding patterns observed in the gels: (I) CC homozygote; (2) CG heterozygote; (3) GG homozygote. Not all bands seen by F-SSCP are shown.

features of nodal involvement, poor histological grade, large tumour size and ErbB2 amplification were all found to be associated with poor outcome in this tumour series (Table 2). Interestingly, the CC genotype was over-represented in patients whose tumours showed the three latter characteristics (Table 1). The CC genotype was not an independent factor for poor survival, however, in a multivariate model that included nodal status, histological grade, tumour size and ErbB2 amplification.

\section{DISCUSSION}

Epithelial cells of the normal mammary gland constitutively produce several cytokines including IL-6 (Basolo et al, 1993). These have been proposed to play a role in the growth and differentiation of mammary epithelial tissue. The levels of IL-6 mRNA and protein are strongly reduced in invasive ductal carcinomas, suggesting an inverse relationship between tumour aggressiveness and the expression of this cytokine (Basolo et al, 1996; Fontanini et al, 1999; Karczewska et al, 2000). Since the common -174 G/C polymorphism has been linked to reduced production of IL-6 (Fishman et al, 1998), we hypothesised that this genetic variant may be associated with a more aggressive breast cancer phenotype.

We observed that homozygosity for the $-174 \mathrm{C}$ allele was significantly associated with poor histological grade and with ductal histology, and showed trends for association with larger tumour size and low oestrogen receptor content (Table 1). In keeping with this, CC homozygous patients also showed worse overall survival compared to the GC/GG patient group (Figure 2), although this was not independent of other established prognostic factors. Our results indirectly support the earlier observations of Basolo and co-workers, who showed that a low tumour level of IL-6 correlated with a more aggressive phenotype (Basolo et al, 1996; Fontanini et al, 1999). The $\mathrm{C}$ allele of the $-174 \mathrm{G} / \mathrm{C}$ polymorphism has been shown to have lower $I L-6$ transcription rates and to be associated with lower expression levels compared to the $G$ allele (Fishman et al, 1998; Terry et al, 2000; Vickers et al, 2002). This might explain our observation of an association between the CC genotype and a more aggressive breast cancer phenotype. Confirmation of this will require direct comparison between the $-174 \mathrm{G} / \mathrm{C}$ genotype and tumour IL-6 expression levels.

At least two other studies have reported an association between low tissue expression of IL-6 and aggressive tumour behaviour (Gandour-Edwards et al, 1995; Basolo et al, 1998). Apart from the current study, however, there has been only one report of an association between the $I L-6-174 \mathrm{G} / \mathrm{C}$ polymorphism and tumour phenotype (Hefler et al, 2003). In contrast to the present results on breast cancer, these workers found that the $\mathrm{C}$ allele was associated with low stage and good prognosis in ovarian cancer patients. A possible explanation may be that IL-6 has different roles in carcinogenesis according to the tumour type. 
Table I The - 174 G/C IL-6 polymorphism and breast cancer phenotype

\begin{tabular}{|c|c|c|c|c|c|}
\hline Feature $(n)$ & CC (\%) & CG (\%) & GG (\%) & $P^{\mathbf{a}}$ & $P^{b}$ \\
\hline Age $\leqslant 57$ years $(117)$ & $23(20)$ & $48(4 I)$ & $46(39)$ & & \\
\hline Node negative (102) & $20(20)$ & $52(51)$ & $30(29)$ & & \\
\hline Node positive (93) & $20(22)$ & $38(4 I)$ & $35(38)$ & NS & NS \\
\hline Well differentiated (29) & $2(7)$ & $13(45)$ & $14(48)$ & & \\
\hline Mod./poorly differentiated (I73) & $39(23)$ & $74(43)$ & $60(35)$ & 0.037 & 0.039 \\
\hline Tumour size $\leqslant 20 \mathrm{~mm}(12 \mathrm{I})$ & $20(17)$ & $55(45)$ & $46(38)$ & & \\
\hline Tumour size $>20$ mm (108) & $29(27)$ & $45(42)$ & $34(31)$ & 0.066 & 0.057 \\
\hline High oestrogen receptor (170) & $32(19)$ & $74(43)$ & $64(38)$ & & \\
\hline Low oestrogen receptor (80) & $23(29)$ & $35(44)$ & $22(27)$ & 0.044 & 0.077 \\
\hline High progesterone receptor (I58) & $34(22)$ & $69(44)$ & $55(34)$ & & \\
\hline Low progesterone receptor (92) & $21(23)$ & $40(43)$ & $31(34)$ & NS & NS \\
\hline Diploid (62) & $12(19)$ & $26(42)$ & $24(39)$ & & \\
\hline Normal p53 (2।4) & $44(21)$ & $92(43)$ & $78(36)$ & & \\
\hline Mutant p53 (42) & $11(26)$ & $20(48)$ & $11(26)$ & NS & NS \\
\hline
\end{tabular}

ap CC vs GG. ${ }^{\text {b }}$ CC vs CG/GG.

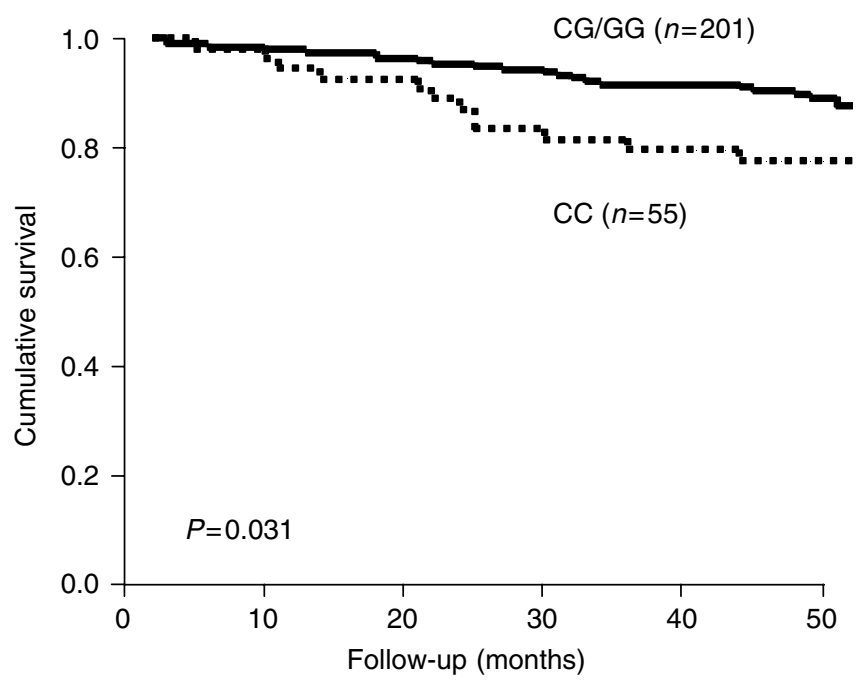

Figure 2 Kaplan-Meier analysis of the overall survival of breast cancer patients grouped according to their genotype for the - 174 G/C IL-6 polymorphism.

Table 2 Univariate survival analysis of established prognostic features and of the $-174 \mathrm{G} / \mathrm{C}$ IL-6 genotype

\begin{tabular}{lcc}
\hline Feature & Relative risk (95\% Cl) & P \\
\hline- I74G/C IL-6 genotype' & $1.99(1.05-3.77)$ & 0.034 \\
Nodal involvement & $2.44(1.66-3.57)$ & $<0.001$ \\
Histological grade & $3.28(1.84-5.85)$ & $<0.001$ \\
Tumour size & $4.44(2.19-9.00)$ & $<0.00$ I \\
Tumour type & $1.24(0.62-2.51)$ & $\mathrm{NS}$ \\
Oestrogen receptor & $1.05(0.82-1.33)$ & $\mathrm{NS}$ \\
Progesterone receptor & $1.03(0.82-1.30)$ & $\mathrm{NS}$ \\
Ploidy & $0.99(0.58-1.70)$ & $\mathrm{NS}$ \\
ErbB2 amplification & $2.05(1.04-4.03)$ & 0.037 \\
\hline
\end{tabular}

CC vs CG/GG genotypes. For all other factors, the groups compared are the same as those shown in Table I.
Elevated serum levels of IL- 6 have been associated with increased tumour burden and more advanced disease in several cancer types including colorectal (Belluco et al, 2000), ovarian (Berek et al, 1991) and breast (Zhang and Adachi, 1999; Bachelot et al, 2003). In a recent study of colorectal cancer, high serum IL-6 levels were linked to the -174 GG genotype, but only in patients with advanced disease (Belluco et al, 2003). It is therefore unclear whether elevated serum levels of IL- 6 are a consequence of or a contributory cause to advanced tumour stage. Further prospective studies will be required to elucidate the relationships between the -174 G/C polymorphism, serum IL-6 levels, normal and tumour tissue IL-6 levels, and the biological phenotype for different cancers. It will also be interesting to determine whether the $-174 \mathrm{C}$ allele is a risk factor for breast cancer, as was shown recently for colorectal cancer (Landi et al, 2003).

We have previously shown significant associations in this breast tumour cohort between polymorphisms in the p53, p21 and luteinising hormone receptor genes and various phenotypic features including histological grade, steroid receptor level and tumour size (Powell et al, 2002, 2003). The present results provide further evidence that genetic variants associated with known functional alterations can influence tumour phenotype.

\section{ACKNOWLEDGEMENTS}

The Gel-Scan 2000 instrument used in this work was purchased from a generous grant provided by the Lotteries Commission of Western Australia.

\section{REFERENCES}

Bachelot T, Ray-Coquard I, Menetrier-Caux C, Rastkha M, Duc A, Blay JY (2003) Prognostic value of serum levels of interleukin 6 and of serum and plasma levels of vascular endothelial growth factor in hormonerefractory metastatic breast cancer patients. Br J Cancer 88: 1721 - 1726

Basolo F, Conaldi PG, Fiore L, Calvo S, Toniolo A (1993) Normal breast epithelial cells produce interleukins 6 and 8 together with tumor-necrosis 
factor: defective IL6 expression in mammary carcinoma. Int J Cancer 55: $926-930$

Basolo F, Fiore L, Fontanini G, Conaldi PG, Calvo S, Falcone V, Toniolo A (1996) Expression of and response to interleukin 6 (IL6) in human mammary tumors. Cancer Res 56: 3118-3122

Basolo F, Fiore L, Pollina L, Fontanini G, Conaldi PG, Toniolo A (1998) Reduced expression of interleukin 6 in undifferentiated thyroid carcinoma: in vitro and in vivo studies. Clin Cancer Res 4: 381-387

Belluco C, Nitti D, Frantz M, Toppan P, Basso D, Plebani M, Lise M, Jessup JM (2000) Interleukin-6 blood level is associated with circulating carcinoembryonic antigen and prognosis in patients with colorectal cancer. Ann Surg Oncol 7: 133-138

Belluco C, Olivieri F, Bonafe M, Giovagnetti S, Mammano E, Scalerta R, Ambrosi A, Franceschi C, Nitti D, Lise M (2003) -174 g $>c$ polymorphism of interleukin 6 gene promoter affects interleukin 6 serum level in patients with colorectal cancer. Clin Cancer Res 9: $2173-2176$

Berek JS, Chung C, Kaldi K, Watson JM, Knox RM, Martinez-Maza O (1991) Serum interleukin-6 levels correlate with disease status in patients with epithelial ovarian cancer. Am J Obstet Gynecol 164: $1038-1042$

Chapman CM, Beilby JP, Humphries SE, Palmer LJ, Thompson PL, Hung J (2003) Association of an allelic variant of interleukin- 6 with subclinical carotid atherosclerosis in an Australian community population. Eur Heart J 24: 1494-1499

Fernandez-Real JM, Broch M, Vendrell J, Gutierrez C, Casamitjana R, Pugeat M, Richart C, Ricart W (2000) Interleukin-6 gene polymorphism and insulin sensitivity. Diabetes 49: 517-520

Fishman D, Faulds G, Jeffery R, Mohamed-Ali V, Yudkin JS, Humphries S, Woo P (1998) The effect of novel polymorphisms in the interleukin-6 (IL-6) gene on IL-6 transcription and plasma IL-6 levels, and an association with systemic-onset juvenile chronic arthritis. J Clin Invest 102: $1369-1376$

Fontanini G, Campani D, Roncella M, Cecchetti D, Calvo S, Toniolo A, Basolo F (1999) Expression of interleukin 6 (IL-6) correlates with oestrogen receptor in human breast carcinoma. $\mathrm{Br} J$ Cancer 80: $579-584$

Gandour-Edwards R, Kapadia SB, Gumerlock PH, Barnes L (1995) Immunolocalization of interleukin-6 in salivary gland tumors. Hum Pathol 26: $501-503$

Grieu F, Joseph D, Norman P, Iacopetta B (2004) Development of a rapid genotyping method for single nucleotide polymorphisms and its application in cancer studies. Oncol Rep, (in press)

Hefler LA, Grimm C, Ackermann S, Malur S, Radjabi-Rahat AR, Leodolter S, Beckmann MW, Zeillinger R, Koelbl H, Tempfer CB (2003) An interleukin-6 gene promoter polymorphism influences the biological phenotype of ovarian cancer. Cancer Res 63: 3066-3068
Ishihara K, Hirano T (2002) IL-6 in autoimmune disease and chronic inflammatory proliferative disease (review). Cytokine Growth Factor Rev 13: $357-368$

Karczewska A, Nawrocki S, Breborowicz D, Filas V, Mackiewicz A (2000) Expression of interleukin-6, interleukin-6 receptor, and glycoprotein 130 correlates with good prognoses for patients with breast carcinoma. Cancer 88: 2061-2071

Landi S, Moreno V, Gioia-Patricola L, Guino E, Navarro M, de Oca J, Capella G, Canzian F, for the Bellvitge Colorectal Cancer Study Group (2003) Association of common polymorphisms in inflammatory genes Interleukin (IL)6, tumor necrosis factor alpha, NFKB1, and peroxisome proliferator-activated receptor delta with colorectal cancer. Cancer Res 63: $3560-3566$

Martinez-Escribano JA, Moya-Quiles MR, Muro M, Montes-Ares O, Hernandez-Caselles T, Frias JF, Alvarez-Lopez MR (2002) Interleukin10 , interleukin-6 and interferon-gamma gene polymorphisms in melanoma patients. Melanoma Res 12: 465-469

Powell BL, Piersma D, Kevenaar ME, van Staveren IL, Themmen AP, Iacopetta B, Berns EM (2003) Luteinizing hormone signaling and breast cancer: polymorphisms and age of onset. J Clin Endocrinol Metab 88: $1653-1657$

Powell BL, van Staveren IL, Roosken P, Grieu F, Berns EM, Iacopetta B (2002) Associations between common polymorphisms in TP53 and p21WAF1/Cip1 and phenotypic features of breast cancer. Carcinogenesis 23: $311-315$

Soong R, Iacopetta BJ, Harvey JM, Sterrett GF, Dawkins HJ, Hahnel R, Robbins PD (1997) Detection of p53 gene mutation by rapid PCR-SSCP and its association with poor survival in breast cancer. Int J Cancer 74: $642-647$

Terry CF, Loukaci V, Green FR (2000) Cooperative influence of genetic polymorphisms on interleukin 6 transcriptional regulation. J Biol Chem 275: $18138-18144$

Vickers MA, Green FR, Terry C, Mayosi BM, Julier C, Lathrop M, Ratcliffe PJ, Watkins HC, Keavney B (2002) Genotype at a promoter polymorphism of the interleukin-6 gene is associated with baseline levels of plasma C-reactive protein. Cardiovasc Res 53: 1029-1034

Yudkin JS, Kumari M, Humphries SE, Mohamed-Ali V (2000) Inflammation, obesity, stress and coronary heart disease: is interleukin- 6 the link? (review). Atherosclerosis 148: 209-214

Zhang GJ, Adachi I (1999) Serum interleukin-6 levels correlate to tumor progression and prognosis in metastatic breast carcinoma. Anticancer Res 19: $1427-1432$

Zheng C, Huang DR, Bergenbrant S, Sundblad A, Osterborg A, Bjorkholm M, Holm G, Yi Q (2000) Interleukin 6, tumour necrosis factor alpha, interleukin-1-beta and interleukin-1 receptor antagonist promoter or coding gene polymorphisms in multiple myeloma. $\mathrm{Br}$ J Haematol 109: $39-45$ 